\title{
The ALDOA Metabolism Pathway as a Potential Target for Regulation of Prostate Cancer Proliferation
}

\author{
Qiwen Kuang',* \\ Yuxiang Liang ${ }^{2, *}$ \\ Yangjia Zhuo ${ }^{2, *}$ \\ Zhiduan $\mathrm{Cai}^{3}$ \\ Funeng Jiang ${ }^{2}$ \\ Jianjiang $X_{i e^{2}}$ \\ Yu Zheng $\mathbb{D}^{4}$ \\ Weide Zhong (D) 1,2,5,6 \\ 'Department of Urology, Guangdong \\ Provincial Institute of Nephrology, Nanfang \\ Hospital, Southern Medical University, \\ Guangzhou, People's Republic of China; \\ ${ }^{2}$ Department of Urology, Guangdong Key \\ Laboratory of Clinical Molecular Medicine \\ and Diagnostics, Guangzhou First People's \\ Hospital, School of Medicine, South China \\ University of Technology, Guangzhou, \\ People's Republic of China; ${ }^{3}$ Department of \\ Urology, The Fifth Affiliated Hospital of \\ Guangzhou Medical University, Guangzhou, \\ Guangdong, People's Republic of China; \\ ${ }^{4}$ Department of Urology, The Second \\ Affiliated Hospital of Guangzhou Medical \\ University, Guangzhou Medical University, \\ Guangzhou, People's Republic of China; \\ ${ }^{5}$ Department of Urology, Dejiang County \\ People's Hospital of Guizhou Province, \\ Dejiang, Guizhou, People's Republic of \\ China; ${ }^{6} \mathrm{~S} c h o o l$ of Medicine, Jinan \\ University, Guangzhou, Guangdong \\ People's Republic of China
}

*These authors contributed equally to this work

Correspondence: Weide Zhong Department of Urology, Guangdong Provincial Institute of Nephrology, Nanfang Hospital, Southern Medical University, 1838, Guangzhoudadaobei, Baiyun District, Guangzhou, People's Republic of China

Tel +862081048312

Fax +862083373322

Email zhongwd2009@live.cn
Background: ALDOA plays an essential role in cancer progression in different human cancers; however, its function has not been understood in prostate cancer $(\mathrm{PCa})$.

Methods: Associations of ALDOA expression with clinicopathological features and patient prognosis in PCa were evaluated based on data obtained from the Taylor database and our clinical tissue microarray. The potential roles of ALDOA in malignant progression were verified using a series of in vivo and in vitro experiments after stable ALDOA overexpression and knockdown in DU145 and PC3 cell lines. An aldolase A inhibitor was used to determine the effects of inhibition of ALDOA on PCa cell proliferation.

Results: Higher expression of ALDOA was positively correlated with the incidence of postoperative metastasis and biochemical recurrence (BCR) and may predict poor prognosis in PCa patients. In vivo experiments demonstrated that overexpression of ALDOA could significantly promote cell proliferation, prolong the cell cycle, and significantly reduce the apoptosis rate of PCa cells. Knockdown of expression of ALDOA could inhibit the proliferation and shorten the cell cycle of PCa cells significantly, with no significant effects on cell apoptosis $(P>0.05)$. In vitro experiments showed that overexpression of ALDOA could significantly promote tumor growth $(P<0.05)$, while treatment with the Aldolase A inhibitor naphthol AS-E phosphate dose-dependently suppressed the growth of PCa cells $(P<0.01)$. The analysis of datasets from the Taylor database showed that there was negative regulatory relationship between the expression of ALDOA and MYPT1 $(P<$ $0.001)$.

Conclusion: Our study revealed that ALDOA played an important role in the progression of PCa. The MYPT1-ALDOA signaling axis may be a new target for the clinical treatment of PCa patients given its negative regulatory relationship. Our study suggests that Aldolase A inhibitors may represent a novel approach to inhibit the growth of PCa.

Keywords: prostate cancer, ALDOA, aldolase A, tumor growth, metastasis

\section{Introduction}

In recent years, the incidence of prostate cancer $(\mathrm{PCa})$ has been increasing worldwide. PCa was identified as the second most common cancer in the world and the fifth leading cause of cancer mortality in men according to the GLOBOCAN project. ${ }^{1}$ The 5 -year survival rate of patients with $\mathrm{PCa}$ is nearly $80 \%$, while the 5 -year survival rate for patients presenting PCa metastasis is only 34\%. Therefore, it is necessary to identify biomarkers for the early diagnosis and as potential therapeutic targets for reducing the invasive capacity and preventing distant metastasis of $\mathrm{PCa}{ }^{2,3}$ 
The nutritional requirements and metabolic pathways of tumors are reprogrammed to meet the rapid growth of malignant cells. Many studies have provided evidence that inhibition of enhanced cancer metabolic activity results in impaired growth of tumor cells. For example, silybin, a glucose transporter (GLUT) inhibitor, is able to induce cell cycle arrest, reduce angiogenesis, and downregulate NF-kB and EGFR activity. ${ }^{4}$ Lonidamine (TH-070) is a hexokinase inhibitor that can cause increased mitochondrial permeability, intracellular acidification, and apoptosis. ${ }^{5}$ Several tumor metabolic characteristics have been used as diagnostic markers and therapeutic targets of multiple malignancies clinically. In addition, several agents are currently being studied in early clinical trials as inhibitors of tumor metabolism. ${ }^{6}$ 2-Deoxyglucose, a competitive inhibitor of G6P isomerase and therefore of glycolysis, is currently under investigation in patients with castration-resistant $\mathrm{PCa}$ and advanced solid tumors ${ }^{7-9}$ and this will open a new field of research toward the development of specific metabolic inhibitors that can be added to currently available chemotherapeutics to increase the efficacy of clinical outcomes of cancer patients. ${ }^{10}$ Abnormal tumor metabolism may play a crucial role in carcinogenesis and cancer progression in PCa. Tumor metabolism is expected to provide new anti-tumor treatments that are more effective than traditional treatments. ${ }^{5}$

Our previous studies demonstrated that miR-30d promoted the proliferation, invasion, and migration of $\mathrm{PCa}$ cells by targeting myosin phosphatase target subunit 1 (MYPT1). ${ }^{11}$ Another study has also indicated that MYPT1 may act as a tumor suppressor in $\mathrm{PCa}$, and its downregulation has been indicated to be an independent prognostic factor of poor outcome of PCa patients. ${ }^{12}$ In addition, a total of 46 proteins that are bound with MYPT1 in PCa cells were identified by tandem affinity purification/mass spectrometry (TAP/MS). Functionally, these proteins were mostly involved in tumor metabolic pathways. ${ }^{12}$ Most of these proteins were associated with the glycolytic pathway and included fructose-bisphosphate aldolase A (Aldolase A), glyceraldehyde-3-phosphate dehydrogenase (GAPDH), enolase 1 (ENO1), pyruvate kinase M1/2 (PKM2), and lactate dehydrogenase A (LDHA) activity. Aldolase A is encoded by ALDOA and is a glycolytic enzyme that catalyzes the reversible conversion of fructose-1,6-bisphosphate to glyceraldehyde 3-phosphate and dihydroxyacetone phosphate.

Evidence from the Human Protein Atlas (https://www. proteinatlas.org/) indicates that ALDOA is a cancer-related gene. Ji et al found that ALDOA functions as an oncogene in highly metastatic pancreatic cancer. ${ }^{13}$ Recent studies have demonstrated that upregulation of ALDOA may promote the glycolysis of cancer cells and may be significantly associated with the development, metastatic potential, and poor prognosis of various kinds of tumors. ${ }^{14-17}$ Chang et al found that down-regulated ALDOA expression could enhance radiotherapy sensitivity of cap-RR (prostate cancer radioresistance) cells, which suggested that the radiotherapy resistance of cap-RR cells could be effectively overcome by regulating ALDOA expression. ${ }^{17}$ However, the biological functions and molecular mechanisms of ALDOA activity underlying PCa have not been fully elucidated. Therefore, we conducted this study to verify the relationship between ALDOA expression and the progression and prognosis of $\mathrm{PCa}$ and to confirm whether ALDOA could be a therapeutic target in the clinical treatment of PCa.

\section{Materials and Methods Ethics Statement}

This study was approved by the Human Study Ethics Committees at Guangzhou First People's Hospital and Guangzhou Medical University of P. R. China. All specimens were handled and anonymized according to due ethical and legal standards.

All animal housing and experiments were conducted in accordance with the guidelines of the Institute for Laboratory Animal Research of Guangzhou Medical University, Guangzhou, P. R. China.

\section{Clinical Tissue Samples and Database}

Tissue microarray (TMA) for immunohistochemistry was purchased from Alenabio (China; Catalog number: PR803c). The TMA contains detailed clinical information about each specimen. Patients that had received treatment with chemotherapy or radiotherapy were excluded. The Taylor database (http://www.ncbi.nlm.nih.gov/geo/query/ acc.cgi?acc $=\mathrm{GSE} 21032$ ), which is a public microarray database of PCa, was used for the analysis of the associations between ALDOA expression and clinical-pathological features of PCa patients. ${ }^{18}$ Table 1 summarizes the clinicopathological data of PCa patients from the TMA and the Taylor dataset.

\section{Cell Culture}

Two PCa cell lines (DU145 and PC3) were acquired from the American Type Culture Collection (ATCC, USA). 
Table I Association Between ALDOA Expression and the Clinicopathological Characteristics of Patients with PCa in the Evaluated Cohorts

\begin{tabular}{|c|c|c|c|c|c|c|}
\hline \multirow[t]{2}{*}{ Clinical Feature } & \multicolumn{3}{|c|}{ IRS of ALDOA Expression in Our Cohort } & \multicolumn{3}{|c|}{ ALDOA Expression in Taylor Dataset } \\
\hline & Case & Mean \pm SD & $P$ & Case & Mean \pm SD & $P$ \\
\hline $\begin{array}{l}\text { ALDOA expression } \\
\text { Benign } \\
\text { Cancer }\end{array}$ & $\begin{array}{c}7 \\
71\end{array}$ & $\begin{array}{l}2.14 \pm 1.22 \\
2.96 \pm 1.92\end{array}$ & 0.145 & $\begin{array}{c}29 \\
150\end{array}$ & $\begin{array}{l}6.34 \pm 0.23 \\
6.39 \pm 0.22\end{array}$ & 0.237 \\
\hline $\begin{array}{l}\text { Age (years) } \\
\quad<66 \\
\geq 66\end{array}$ & $\begin{array}{l}24 \\
47\end{array}$ & $\begin{array}{l}3.04 \pm 2.01 \\
2.91 \pm 1.90\end{array}$ & 0.795 & $\begin{array}{l}125 \\
25\end{array}$ & $\begin{array}{l}6.39 \pm 0.23 \\
6.42 \pm 0.20\end{array}$ & 0.617 \\
\hline $\begin{array}{l}\text { Serum PSA }(\mathrm{ng} / \mathrm{mL}) \\
\quad<4 \\
\geq 4\end{array}$ & $\begin{array}{l}- \\
-\end{array}$ & $\begin{array}{l}- \\
-\end{array}$ & - & $\begin{array}{c}24 \\
123\end{array}$ & $\begin{array}{l}6.41 \pm 0.23 \\
6.39 \pm 0.22\end{array}$ & 0.696 \\
\hline $\begin{array}{l}\text { Gleason score } \\
\quad<8 \\
\geq 8\end{array}$ & $\begin{array}{l}23 \\
41\end{array}$ & $\begin{array}{l}2.22 \pm 1.882 \\
3.39 \pm 1.745\end{array}$ & 0.015 & $\begin{array}{l}117 \\
22\end{array}$ & $\begin{array}{l}6.38 \pm 0.21 \\
6.45 \pm 0.26\end{array}$ & 0.158 \\
\hline $\begin{array}{l}\text { Pathological stage } \\
<\mathrm{T} 3 \mathrm{~A} \\
\geq \mathrm{T} 3 \mathrm{~A}\end{array}$ & $\begin{array}{l}46 \\
24\end{array}$ & $\begin{array}{l}2.61 \pm 1.98 \\
3.75 \pm 1.51\end{array}$ & 0.009 & $\begin{array}{l}86 \\
55\end{array}$ & $\begin{array}{l}6.37 \pm 0.22 \\
6.43 \pm 0.21\end{array}$ & 0.096 \\
\hline $\begin{array}{l}\text { Metastasis } \\
\text { No } \\
\text { Yes }\end{array}$ & $\begin{array}{c}61 \\
9\end{array}$ & $\begin{array}{l}2.98 \pm 2.00 \\
3.11 \pm 1.17\end{array}$ & 0.788 & $\begin{array}{c}122 \\
28\end{array}$ & $\begin{array}{l}6.37 \pm 0.21 \\
6.48 \pm 0.25\end{array}$ & 0.019 \\
\hline $\begin{array}{l}\text { Overall survival } \\
\text { Alive } \\
\text { Die }\end{array}$ & - & - & - & $\begin{array}{c}131 \\
19\end{array}$ & $\begin{array}{l}6.38 \pm 0.21 \\
6.48 \pm 0.29\end{array}$ & 0.073 \\
\hline $\begin{array}{l}\text { PSA failure } \\
\text { Negative } \\
\text { Positive }\end{array}$ & - & - & - & $\begin{array}{c}104 \\
36\end{array}$ & $\begin{array}{l}6.36 \pm 0.21 \\
6.47 \pm 0.22\end{array}$ & 0.008 \\
\hline
\end{tabular}

Notes: "-" Indicates there is a lack of relative information of patients in our cohort. The bold font indicates a $P$ value less than 0.05 .

Abbreviations: IRS, immunoreactivity scores; PCa, prostate cancer; PSA, prostate-specific antigen; ALDOA, Fructose-bisphosphate aldolase A.

They were, respectively, treated with RMPI 1640 medium (HyClone, USA; Cat No: SH30809-01B) or DMEM medium (HyClone, USA; Cat No: SH30022.01B). The medium was supplemented with $10 \%$ fresh fetal bovine serum (FBS) (Gibco, USA; Cat No: 10270-106) and antibiotics (penicillin $(100 \mathrm{U} / \mathrm{mL})$-streptomycin $(100 \mu \mathrm{g} / \mathrm{mL}))$. All the cells were cultured in an incubator $\left(37^{\circ} \mathrm{C}\right.$, containing $5 \%$ carbon dioxide), and all the experiments were conducted with actively proliferating cells.

\section{Plasmid Construction and Transfection}

The Plv.O plasmid (purchased from Danvers, USA) was used as the backbone vector for the construction of the ALDOA overexpression plasmid, while the Plv.I plasmid was used to construct the ALDOA shRNA plasmid. They were constructed by the HYY Medical Company
(Guangzhou, China) based on a lentivirus with the open reading frame of the ALDOA gene. The ALDOA overexpression sequence comprised the CDS sequence of the ALDOA gene mRNA coding sequence. The target sequences of ALDOA shRNA in the DU145 and PC3 cell lines were 5'-GCCAGTATGTGACCGAGAA-3' and 5'-GGCGTTGTGTGCTGAAGAT-3', respectively. The constructed ALDOA overexpression and shRNA plasmids were used for cell transfection studies.

\section{Immunohistochemistry}

The protein expression levels of ALDOA and Ki-67 and PCNA in the tissues were analyzed by immunohistochemistry and the immunohistochemistry score (IRS) according to the method of our previous study. ${ }^{11,19}$ The anti-Ki-67 antibody (1: 100) was purchased from Shanghai Affinity 
Biotechnology (China; Cat. No: af0198). The anti-PCNA antibody (1: 50) was purchased from Zhong Shan Jinqiao Biological Technology (China; Cat. No: za0336). The antiALDOA antibody (1: 800) was purchased (HPA004177, Sigma-Aldrich Co. LLC, USA). The IRS was used to evaluate the expression level of ALDOA in PCa tissues. The tumor sample was considered to have high expression of ALDOA when IRS $\geq 5$, while it was considered low expression of ALDOA when IRS $<5$.

\section{Western Blotting Analysis}

The expression levels of ALDOA protein in all cell lines were detected by Western blotting analysis after cell transfection. Total protein was extracted 48 hours after cell transfection and was used in the Western blotting experiments. A total of $40 \mathrm{ug}$ protein was added to SDS-PAGE gel for electrophoresis and transferred to Hybond nitrocellulose membrane (GE Healthcare). The membrane was blocked with $5 \%$ skim milk and incubated with antiALDOA (1: 1000), and anti-GAPDH antibody (1: 20,000, 10494-1-AP, Proteintech Group, Inc., USA), or anti- $\beta$-actin (1: 2000, BM0627, Santa Cruz Biotechnology, USA). The Super Signal West PICO fluorescence assay (Pierce Biotechnology) was used to detect the protein bands. GAPDH or $\beta$-actin was used as the control for normalization.

\section{Cell Proliferation Assay}

According to our previous studies, ${ }^{11,19}$ PCa cells were cultured for 24 hours after transfection and then made into a single-cell suspension. The cells were seeded into 96-well plates with suspensions containing 2000 cells per well and cultured for 4, 24, 48, and 72 hours, respectively, after pre-culture $\left(37^{\circ} \mathrm{C}, 5 \% \mathrm{CO}^{2}\right)$. The plate was incubated in the incubator for 0.5 to 4 hours with $20 \mu \mathrm{L} \mathrm{CCK}-8$ solution (Beyotime, China; Cat. No: C0039). The absorbance (OD value) at $450 \mathrm{~nm}$ was measured with a microplate reader, and the cell growth curve was plotted over time.

\section{Cell Cycle and Apoptosis Assay}

For cell cycle experiments, cells were collected in singlecell suspension and washed twice with precooled PBS. The cells were resuspended in pre-cooled $70 \%$ ethanol and fixed overnight at $4{ }^{\circ} \mathrm{C}$ or kept at $-20^{\circ} \mathrm{C}$ for long-term fixation. Subsequently, the cells were washed with $1 \mathrm{~mL}$ PBS and incubated at $4{ }^{\circ} \mathrm{C}$ in the dark for 30 minutes with $500 \mathrm{~mL}$ PBS (including $5 \mu \mathrm{g} / \mathrm{mL}$ propidium iodide (PI),
$100 \mu \mathrm{g} / \mathrm{mL}$ RNase A, and $0.2 \%$ Triton X-100). For cell apoptosis experiments, cells were collected in single-cell suspension and washed with precooled PBS and Binding Buffer, in turn. The cell suspension was prepared at 100 $\mu \mathrm{L}$ containing $1 \times 10^{5}$ to $1 \times 10^{6}$ cells. To each sample, 5 $\mu \mathrm{L}$ Annexin v-APC and $10 \mu \mathrm{L}$ 7AAD were added and then incubated at room temperature in the dark for 15 minutes. Next, $400 \mu \mathrm{L}$ precooled Binding Buffer was added to resuspend the mixture. Flow cytometry was used to detect apoptotic cells. Both results were analyzed using Flowjo software.

\section{Xenograft Tumor Model in Nude Mice}

All animal experiments in this study were conducted in accordance with the guidelines of the Institute for Laboratory Animal Research of Guangzhou Medical University, Guangzhou, P. R. China. In total, 32 nude mice (male, 4-6 weeks old, Sun Yat-sen University Laboratory Animal Center) were randomly divided into 4 groups. A $100 \mu \mathrm{L}$ suspension containing $4.0 \times 10^{6}$ control cells was subcutaneously inoculated on the left side of the mice, while suspensions containing ALDOA overexpressing or shRNA cells were inoculated at the right side. After tumor formation, tumor size was measured once every three days, and tumor volumes were calculated using the following formula: $\mathrm{V}\left(\mathrm{mm}^{3}\right)=$ width $^{2}\left(\mathrm{~mm}^{2}\right)$ $\mathrm{x}$ length $(\mathrm{mm}) / 2$. After 4 weeks, the nude mice were euthanized in strict accordance with the procedures formulated by Guangzhou Medical University Guidelines.

\section{Treatment with Aldolase A Inhibitor Naphthol AS-E Phosphate and Evaluation of Prostate Cancer Cell Proliferation}

We searched the Drug Bank for four inhibitors of Aldolase A (https://www.drugbank.ca/drugs/DB08240). After screening, naphthol AS-E phosphate was finally selected as the experimental drug. PC3 and DU145 cells were divided into the control group and the naphthol AS-E phosphate treatment groups (concentrations: $0,2.5 \mu \mathrm{M}, 5$ $\mu \mathrm{M}, 10 \mu \mathrm{M}$, and $20 \mu \mathrm{M}$ ) and then assessed using the cell proliferation assay. Suspensions containing 8000 cells (200 $\mu \mathrm{L} /$ well) were seeded in a 96-well plate and cultured for 24 hours. After replacing the medium, the corresponding treatment of naphthol AS-E phosphate was added and cells were cultured for an additional 24 hours. Lastly, 20 $\mu \mathrm{L}$ CCK-8 solution was added to each well, and cells were 
incubated for an additional 0.5 to 4 hours. The absorbance at $450 \mathrm{~nm}$ was measured using a microplate reader.

\section{Molecular Docking of Naphthol AS-E Phosphate with Aldolase A}

We downloaded the protein crystal structure of Aldolase A from the Protein data bank (PDB) database, and we used molecular docking to determine its active binding side. The procedure used for molecular docking experiments is outlined below.

Preparation of the receptor: We opened the selected protein molecule 1ALD (Aldolase A) files with AUTODOCK TOOLS. The polar hydrogen nucleus Kollman charge was added and then the whole protein was inserted in the search box for the docking conformation. The following pocket information was obtained: center_x $=-50.757$, center $\_y=46.841$, center_z $=49.371$, size $\_\mathrm{x}=122$, size $\_\mathrm{y}=102$, size_ $\mathrm{z}=118$, spacing $=0.531$, and num_modes $=10$.

Preparation of the ligand: The CAS number of naphthol AS-E phosphate provided was 18228-17-6. The small molecular structure file was searched and downloaded (http://www. chemicalbook.com/Search.aspx?Keyword=18228-17-6). The Gasteiger charge was added and the output file was stored as a PDBQT format file.

Docking: We used AUTODOCK software to pair the ligand molecule to the established receptor pocket and output the TOP10 molecules.

\section{Statistical Analysis}

The statistical software SPSS 19.0 (SPSS Inc., Chicago, IL, USA) was used for all analyses. Categorical variables were analyzed using Pearson's chi-square test. The two independent sample $t$-test was used to analyze quantitative results. The Kaplan-Meier method and Log-rank test were used for the clinical survival analysis of PCa patients. Univariate and multivariate analysis of the COX regression model was used to evaluate whether ALDOA and various clinical indicators of PCa could be independent predictors of survival without BCR. The differences between data at different time points from the two groups were compared with the repeatedmeasurement variance method. $P<0.05$ was considered statistically significant. Continuous variables are shown as mean \pm standard deviations (SD).

\section{Results}

\section{ALDOA Gene Selection}

Our research has found that MYPT1 is a target gene directly regulated by miR-30d. The 46 proteins that are bound with MYPT1 were obtained by tandem affinity purification/mass spectrometry (TAP/MS). Combined with the GO/KEGG pathway analysis, it was found that most of these proteins in the potential downstream signaling pathway of MYPT1 were associated with the glycolytic pathway. We selected 7 genes from the 46 selected genes that bind to MYPT1and the differently expressed genes of PCa patients with nonmetastatic and biochemical recurrent in Taylor database. Among them, ALDOA encodes ALDOLASE A which is a glycolytic enzyme and catalyzes the reversible conversion of fructose-1,6-bisphosphate to glyceraldehyde 3-phosphate and dihydroxyacetone phosphate. Evidence from the Human Protein Atlas (https://www.proteinatlas.org/) indicates that ALDOA is cancer-related. So we selected ALDOA as the target gene. The gene selection of ALDOA is shown in Figure 1.

\section{Expression of ALDOA Associated with Aggressive Progression and Metastasis of PCa Patients}

Immunohistochemistry analysis was performed on TMA samples from 78 patients (including 71 primary PCa tissues and 7 adjacent non-cancerous prostate tissues) to detect the expression of ALDOA protein and its relationship with clinicopathological characteristics (Figure 2A and B).

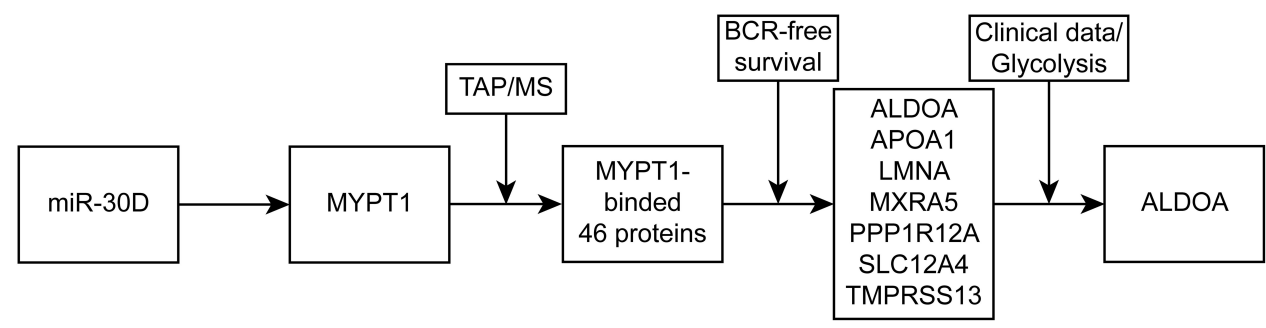

Figure I Flow chart showing the selection of ALDOA. 
A
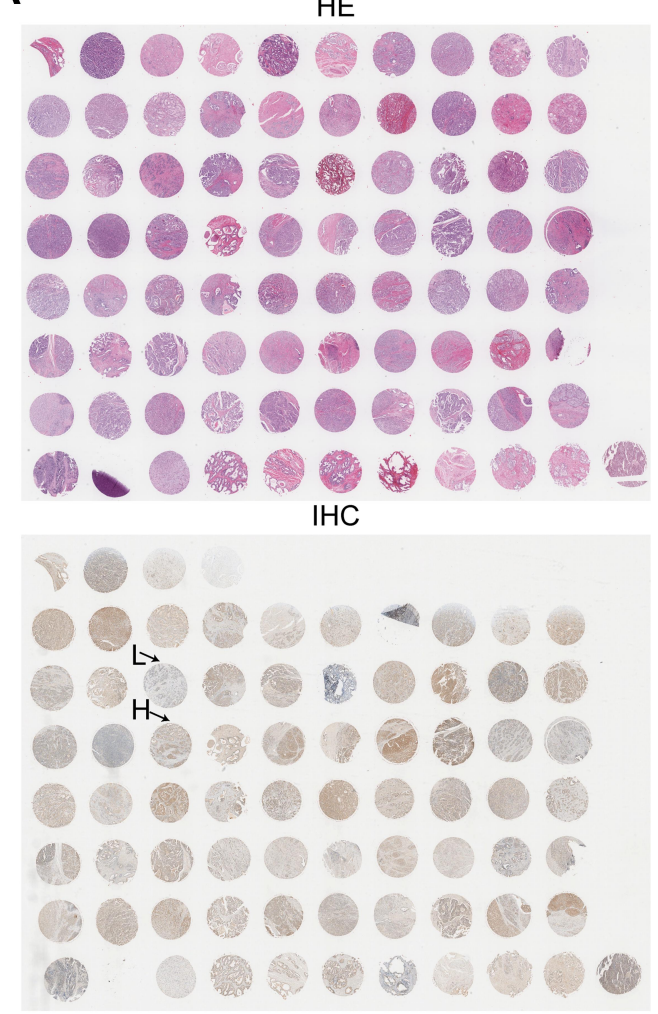

C

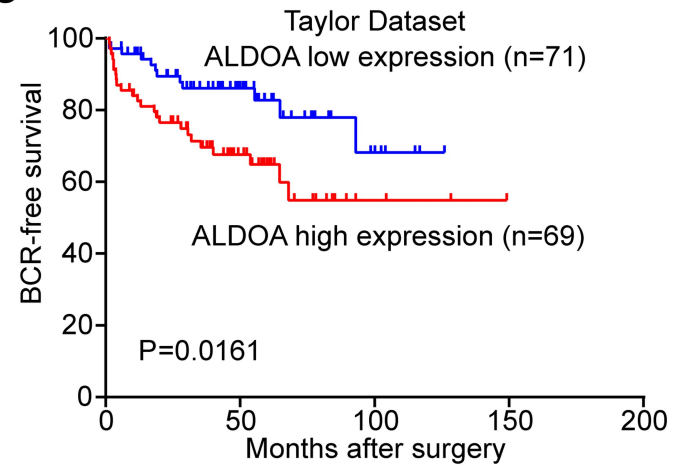

B
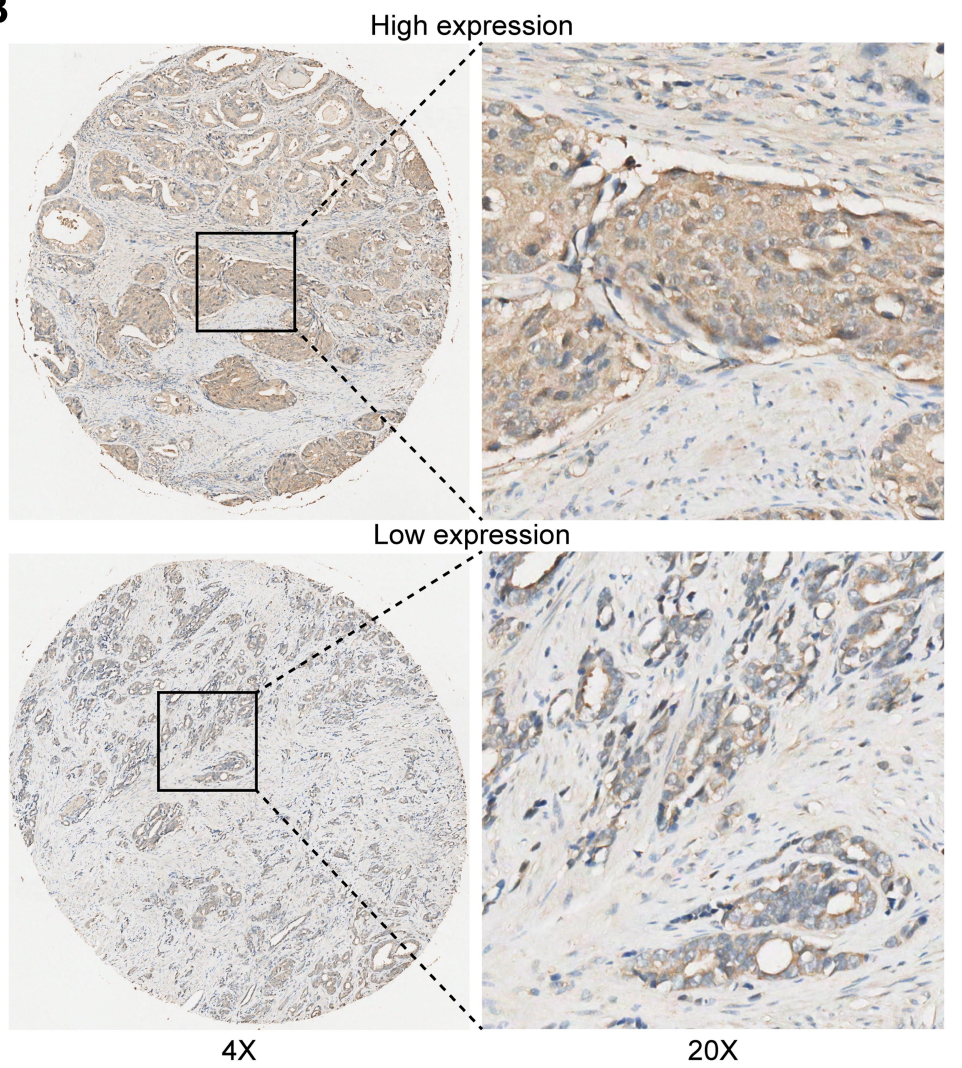

D

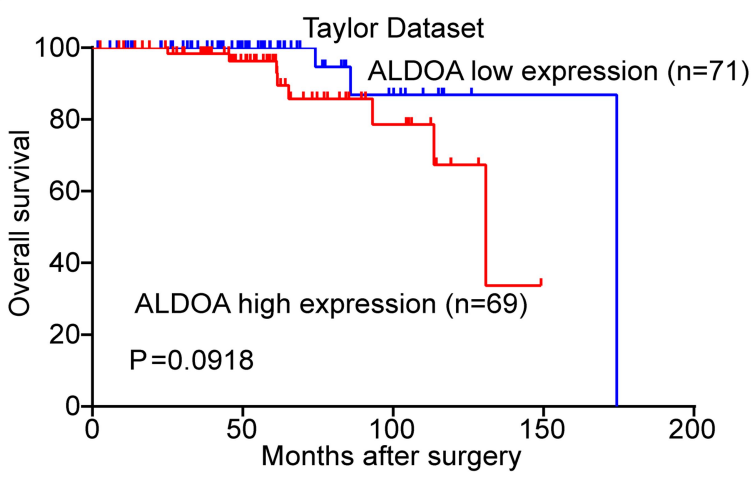

Figure 2 Immunohistochemical staining for ALDOA in PCa and adjacent benign tissues and survival analysis of ALDOA using data extracted from the Taylor database. (A) A full view of the immunohistochemistry staining for ALDOA in the TMA. (B) Immunostaining showing the high and low expression of ALDOA. Magnification on the left panel is $\times 4$. The magnification of the right panel is $\times 20$. (C) Kaplan-Meier curves showed that there was a significant difference in BCR-free survival between patients with high and low expression of ALDOA in the Taylor dataset $(P=0.0161)$. (D) There was no significant difference in overall survival between the two groups $(P=0.0918)$.

According to the subgroup analysis based on the Gleason score $(<8$ and $\geq 8)$ and pathological stage $(<\mathrm{T} 3 \mathrm{~A}$ and $\geq$ T3A), the IRS of ALDOA protein in PCa tissues with high Gleason score $(\geq 8)$ and advanced pathological stage $(\geq$ T3A) was respectively higher than that with low Gleason score $(<8)$ and early pathological stage $(<\mathrm{T} 3 \mathrm{~A})(3.39 \pm$ 1.745 vs $2.22 \pm 1.882, P=0.015$, and $3.75 \pm 1.51$ Vs $2.61 \pm$ $1.98, P=0.009$, respectively) (Table 1 ).
The association between ALDOA expression and various clinicopathological characteristics and prognosis of patients with PCa was analyzed based on the Taylor dataset. As shown in Table 1, the results showed that high expression of ALDOA was positively correlated with the incidence of postoperative metastasis and BCR in PCa patients $(P=$ 0.019 and $P=0.008$, respectively). However, there was no significant correlation between the expression of ALDOA, 
Table 2 Prognostic Value of ALDOA Expression Levels for the Biochemical Recurrence-Free Survival of PCa Patients on Univariate and Multivariate Analyses by Cox Regression Analyses

\begin{tabular}{|l|l|l|l|l|}
\hline \multirow{2}{*}{} & \multicolumn{1}{|c|}{ Univariable Analysis } & \multicolumn{2}{c|}{ Multivariable Analysis } \\
\cline { 2 - 5 } & HR (95\% Cl) & $P$ & HR (95\% CI) & P \\
\hline Preoperative serum PSA $(\geq 4$ vs $<4)$ & $1.311(0.508-3.38 I)$ & 0.576 & $0.816(0.304-2.191)$ & 0.964 \\
\hline Gleason score $(\geq 8$ vs $<8)$ & $11.540(5.810-22.921)$ & 0.000 & $7.367(3.491-15.547)$ & 0.000 \\
\hline Pathological tumor stage $(\geq \mathrm{T} 3 \mathrm{~A}$ vs $<\mathrm{T} 3 \mathrm{~A})$ & $5.221(2.559-10.655)$ & 0.000 & $2.935(1.341-6.424)$ & 0.007 \\
\hline ALDOA (high vs low) & $2.288(1.143-4.581)$ & 0.019 & $1.886(0.905-3.933)$ & 0.090 \\
\hline
\end{tabular}

Abbreviations: $\mathrm{HR}$, hazard ratio; $\mathrm{Cl}$, confidence interval.

age, or serum prostate-specific antigen (PSA) levels, Gleason score, pathological stage, or mortality $(P>0.05)$.

\section{High Expression of ALDOA Predicted Poor Prognosis of PCa}

The univariate and multivariate analyses and the COX regression model were used to evaluate the predictive value of ALDOA protein expression for the risk of BCR in PCa patients (Table 2). Both univariate and multivariate analyses demonstrated that the tumor pathological stage [HR: 5.22 (2.56-10.65)] and Gleason score [HR: 11.54 (5.81-22.921)] may be independent predictors of postoperative BCR risk in PCa patients. However, high expression of ALDOA was associated with shorter BCR-free survival but did not function as an independent prognostic factor of PCa patients, as shown in the multivariate analysis (hazard ratio [HR]: 1.89 [0.91-0.393]).

Survival outcomes were analyzed using the KaplanMeier and Log-rank method and patients were stratified according to the median ALDOA expression level. The survival curves revealed that high expression of ALDOA was significantly associated with low BCR-free survival $(P=0.016$, Figure 2C). However, there was no significant difference in the overall survival rate between the two groups $(P=0.0918$, Figure 2D), which suggested that the high expression of ALDOA in PCa was closely associated with the poor prognosis of patients.

\section{ALDOA Promoted Proliferation, Prolonged the Cell Cycle, and Induced the Apoptosis of PCa Cells in vitro}

ALDOA overexpression and knocked-down expression cell lines were successfully constructed by transfecting DU145 and PC3 cell lines with lentiviral vectors. Meanwhile, the corresponding cell lines transfected by the respective empty vectors were constructed as the NC groups. Western blotting analysis showed that the protein expression of ALDOA in the ALDOA overexpressing group was significantly higher than that of the NC groups, while it was markedly reduced in the ALDOA knockdown group compared with the NC groups (Figure 3A).

Cell proliferation (CCK-8 assays) results showed that the proliferative ability of PC3 and DU145 cells with overexpressing ALDOA was markedly enhanced compared with that of the NC group, $P<0.01$ (Figure 3B). Meanwhile, the cell proliferative ability of PC3 and DU145 cells with ALDOA knockdown was decreased compared with that of the $\mathrm{NC}$ group $P<0.01$ (Figure 3B). Cell cycle experiments showed that the $\mathrm{S}+\mathrm{G} 2$ phase of both PC3 and DU145 cells with ALDOA overexpression was significantly prolonged $(P<$ 0.01 ) (Figure $3 \mathrm{C}$ and $\mathrm{E}$ ). Instead, the $\mathrm{S}+\mathrm{G} 2$ phase of the ALDOA knockdown cells was shortened significantly compared to those of $\mathrm{NC}$ groups $(P<0.01)$ (Figure 3D and F). The results of the apoptosis experiment indicated that the rates of apoptosis in the ALDOA overexpression group with PC3 and DU145 cells were significantly lower than those in the control group (Figure 3G and I). However, there was no significant difference between the ALDOA knockdown groups and the corresponding control groups with regard to the apoptosis rate $(\mathrm{P}>0.05)$ (Figure $3 \mathrm{H}$ and $\mathrm{J})$.

\section{ALDOA Promoted Tumor Growth of $\mathrm{PCa}$ in Nude Mice in vivo}

DU145 and PC3 cell lines with stable ALDOA overexpression or ALDOA knockdown and their corresponding empty vector control cell lines were injected subcutaneously into nude mice to form the tumor xenograft model. As shown in Figure $4 \mathrm{~A}$ and $\mathrm{B}$, in both the DU145 treatment groups, 4 mice of each group died within the 4 weeks of treatment. The growth rates of tumors 
A

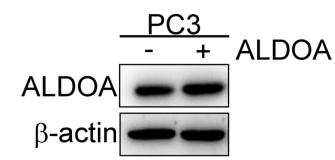

B

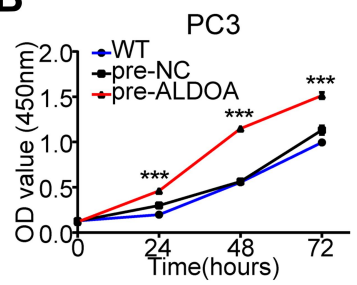

C
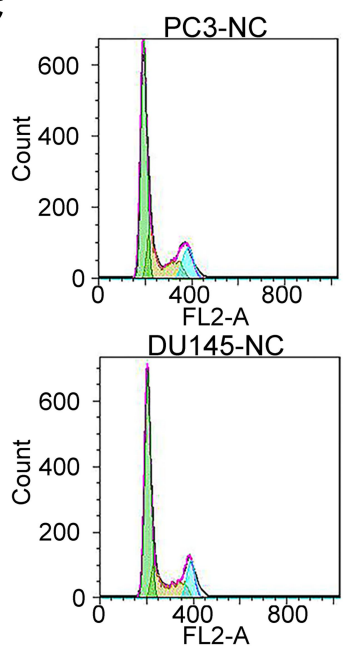

E

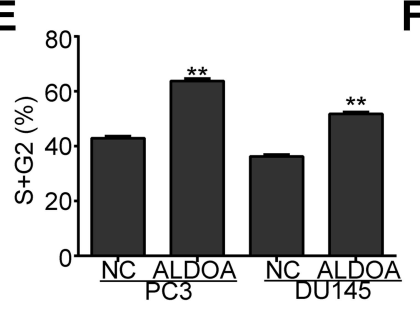

I

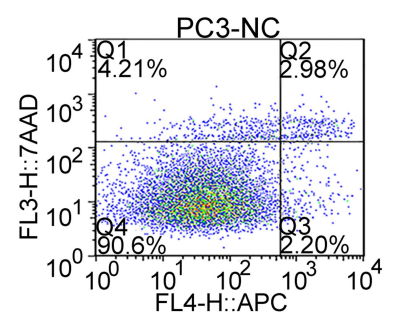

DU145-NC

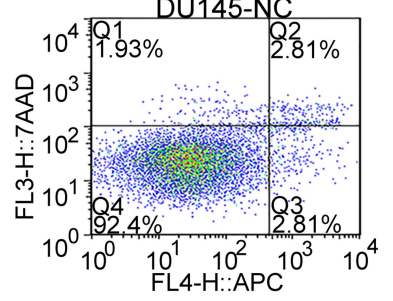

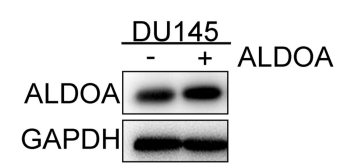
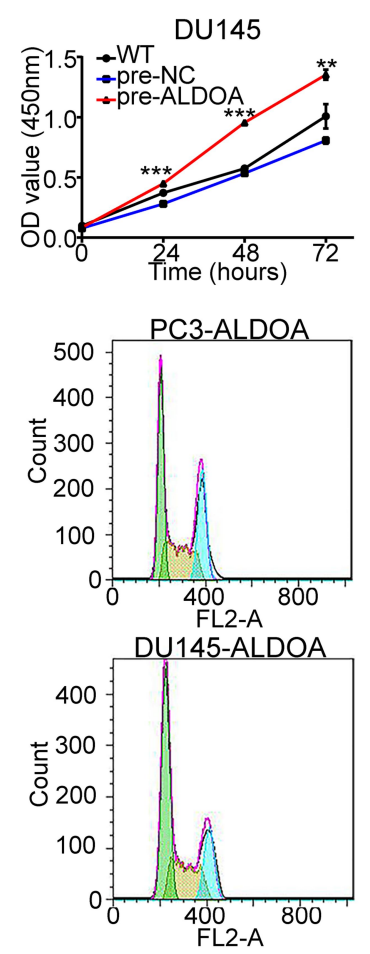

F
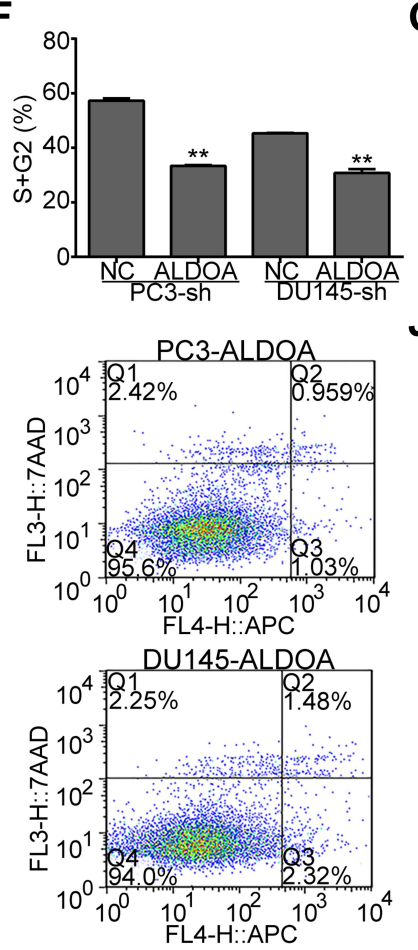
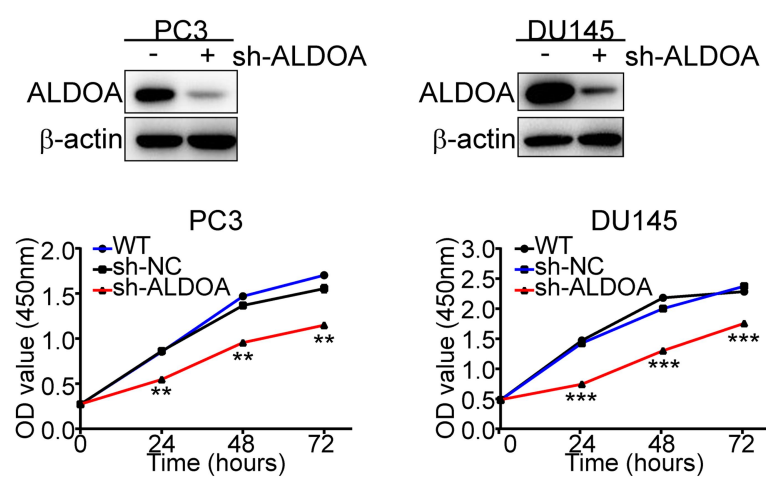

D
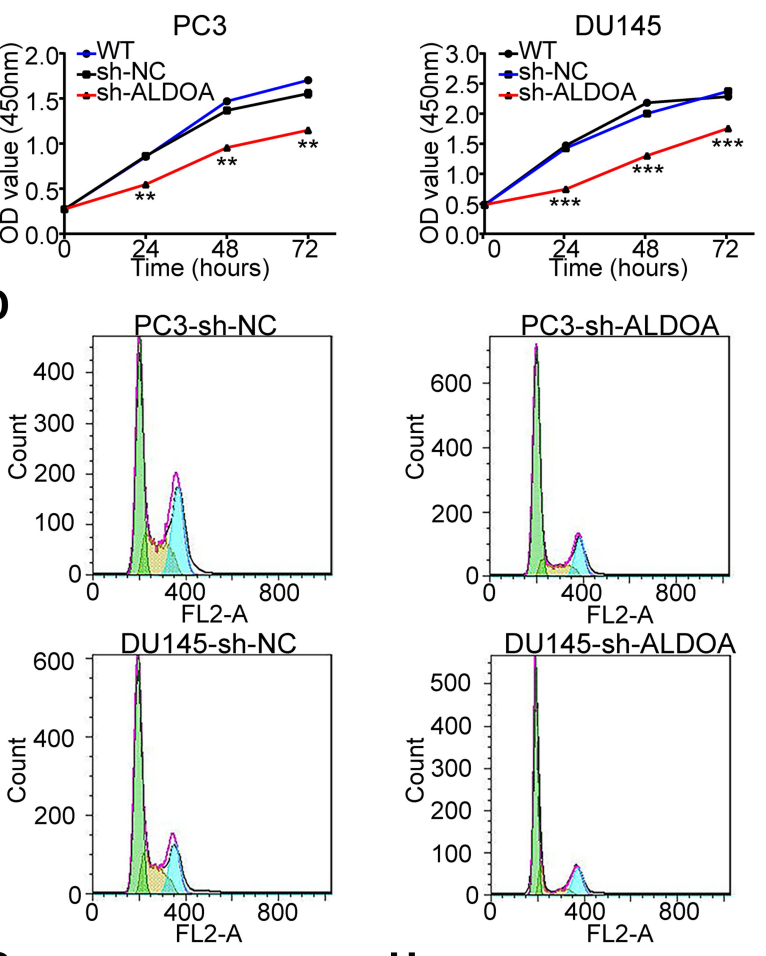

G
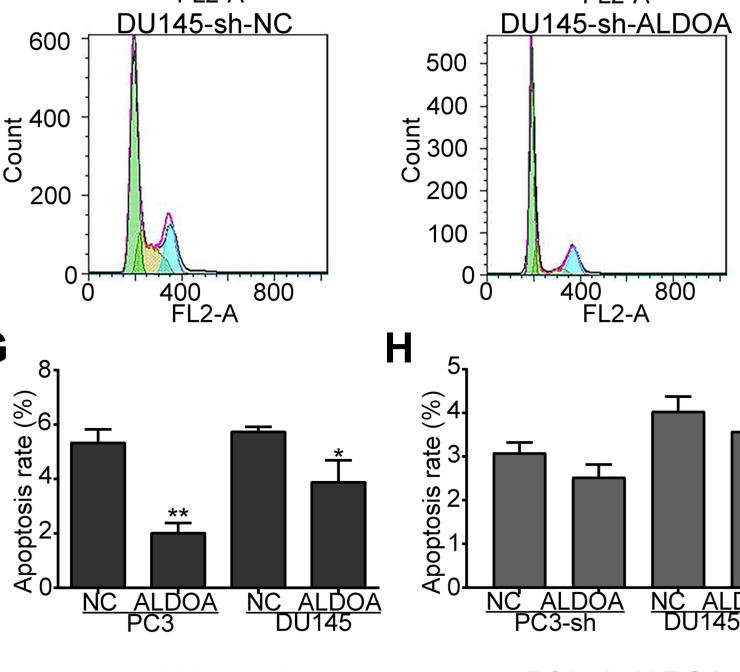

H
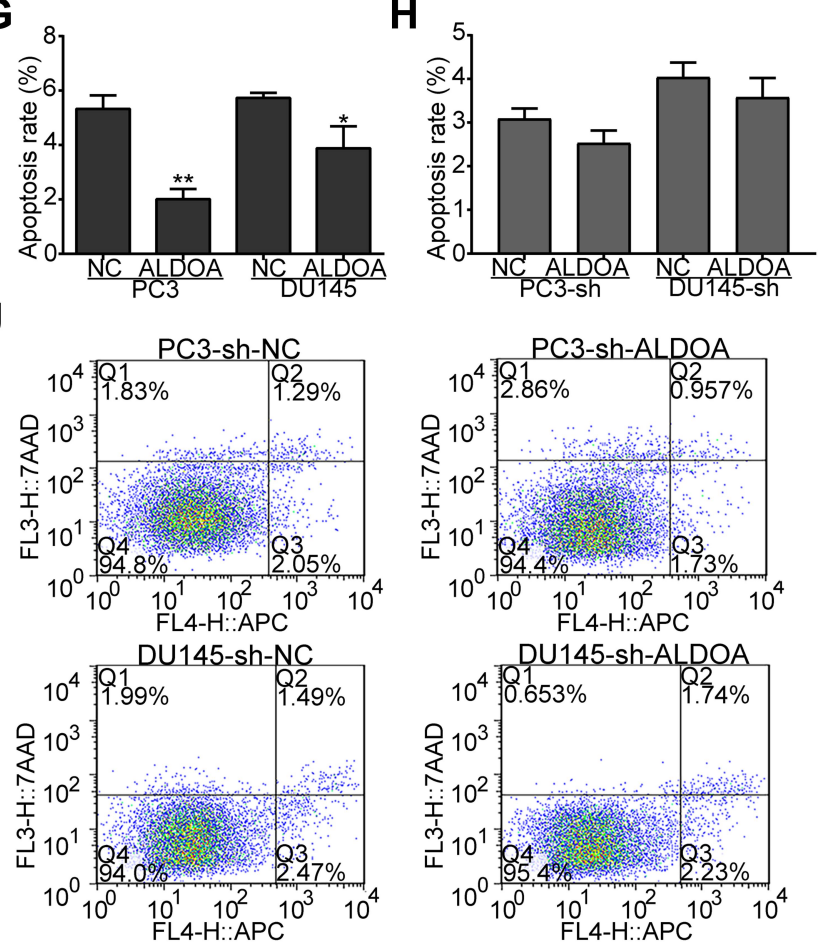

Figure 3 ALDOA promotes the proliferation of PCa cells, prolongs the cell cycle, and suppresses apoptosis in PC3 and DUI 45 cell lines. (A) ALDOA levels were verified by Western blotting after transfection. (B) ALDOA overexpression enhanced the proliferation of PC3 and DUI45 cells in vitro, while ALDOA knockdown inhibited the proliferative effects. (C, D, E, F) ALDOA overexpression prolonged the cell cycle of PC3 and DUI45 cells in vitro, while ALDOA knockdown suppressed the effects on the cell cycle. (G, H, I, J) ALDOA overexpression suppressed apoptosis of PC3 and DUI 45 cells, while ALDOA knockdown did not induce significant apoptosis. $* P<0.05$, **P $<$ $0.01, * * *<<0.001$ compared with the NC group. 
formed by ALDOA overexpressed DU145 and PC3 cells were significantly accelerated, and the tumor volume and weight were significantly higher than those of the NC groups $(P<0.05)$ (Figure 4A and $\mathrm{C})$. The growth rates of tumors formed by DU145 and PC3 cells with ALDOA knockdown were slowed, and the tumor volume and weight were lower than those of the NC groups. However, there was no significant difference between the two groups $(P>0.05)$ (Figure 4B and D).

We conducted an immunohistochemical analysis to detect the expression of the proliferation marker Ki67 and PCNA in the transplanted tumor tissues. The IRS of PCNA showed that ALDOA overexpression promoted cell proliferation significantly (PC3: $P<0.015$; DU145: $P<$ 0.001; Figure 4E and F), and ALDOA knockdown suppressed cell proliferation $(P<0.05$; Figure $4 \mathrm{G}$ and $\mathrm{H})$. The IRS of Ki67 in the PC3-pre-ALDOA group was significantly higher than that of the $\mathrm{NC}$ group $(P<0.001$; Figure $4 \mathrm{~F})$, but there was no significant difference between the other groups (Figure 4E, G and H).

\section{ALDOA Expression Negatively Correlated with MYPTI Expression Based on the Taylor Database}

The prognostic potential of the MYPT1/ALDOA combination in the BCR-free survival of PCa patients was confirmed by the data from the Taylor Dataset $(P=0.044, P=0.011$, Figure $5 \mathrm{~A}$ and $\mathrm{C}$ ). There was no significant correlation between MYPT1 and ALDOA expression and the overall survival rate (Figure 5B). The expression of ALDOA was negatively correlated with MYPT1 expression in patients with $\mathrm{PCa}$ as evaluated using Pearson's correlation analysis based on the Taylor database $(P<0.001$; Figure 5D).

\section{Naphthol AS-E Phosphate Inhibited the Proliferation of PCa Cells in vitro}

Naphthol AS-E phosphate is an Aldolase A competitive inhibitor (https://www.rcsb.org/structure/2ot1). The results of the cell proliferation assay showed that the IC50 of naphthol AS-E phosphate inhibiting cell viability was $18.21 \mu \mathrm{moL} / \mathrm{L}$ in the PC3 cell groups and $32.32 \mu \mathrm{moL} / \mathrm{L}$ in the DU145 cell groups, respectively. When the concentration of Naphthol AS-E phosphate was greater than 2.5 $\mu \mathrm{moL} / \mathrm{L}$, the cell viability of the PC3-treated groups gradually decreased dose-dependently with increasing concentration $(P<0.001$; Figure $5 \mathrm{E})$. The cell viability of the DU145 groups treated with a higher concentration of naphthol AS-E phosphate (10 and $20 \mu \mathrm{moL} / \mathrm{L})$ was lower than that of the control group $(P<0.001$; Figure 5F).

\section{Molecular Docking Results of Naphthol AS-E Phosphate to Aldolase A}

As shown in Figure 5G, molecule naphthol AS-E phosphate is well incorporated into pockets formed by the lamina, loop region, and small spiral structure. The orange grid represents the van der Waals volume of the small molecule naphthol AS-E phosphate. Figure $5 \mathrm{H}$ presents the proposed action mode and the amino acids within the distance of the small molecule naphthol AS-E phosphate. All these amino acids are polar except for ALA-31, GLY302, and ALA-362 and the phosphoric acid residues of the molecule forming two hydrogen bonds with the amino acids GLU-34 and ARG-42, which indicates that polar attractive forces may play an essential role in the binding pocket. Furthermore, nonpolar forces may exist between the naphthalene ring of the naphthol AS-E phosphate molecule and the benzene ring of TYR-363. In conclusion, both polar and non-polar activities play an essential role in the binding of naphthol AS-E phosphate and fructose bisphosphate aldolase A. Table 3 shows the affinity data between ligands and receptors of 10 molecular models obtained by the molecular docking of naphthol AS-E phosphate and aldolase A.

\section{Discussion}

Tumor cells accelerate glucose uptake through the "Warburg effect", and elevated aerobic glycolysis becomes the primary metabolic mode for cancer cells to meet the energy requirements of rapid growth and proliferation of tumor cells. ${ }^{21}$ In addition, an elevated glycolytic phenotype has been found in the advanced stages of PCa. GLUT1, a key enzyme of the glycolytic pathway, is a glucose transmembrane transporter. ${ }^{22}$ Several factors can increase the expression of GLUT1 on cell membranes and consequently enhance glucose uptake. It has been reported that GLUT1 is overexpressed in $\mathrm{PCa}^{23}$ Fendt et al found that metformin treatment decreased glucose oxidation and increased dependency on reductive glutamine metabolism in cancer cell lines and in a mouse model of $\mathrm{PCa}$, which suggests that interfering with glutamine metabolism may synergize with metformin to improve outcomes in patients with $\mathrm{PCa}^{24}$

ALDOA plays a vital role in glycolysis and the maintenance of sugar homeostasis, ${ }^{25}$ and its increased activity 
A

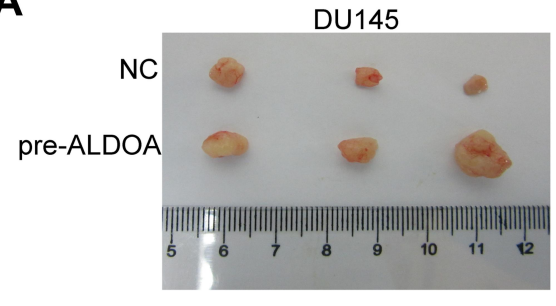

B

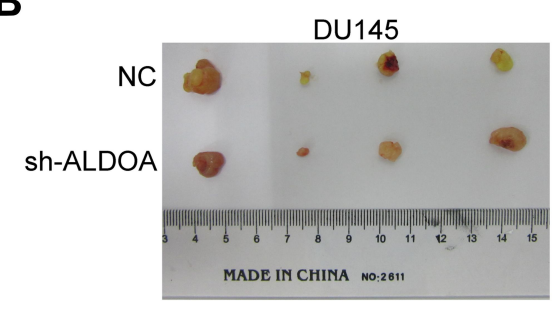

C

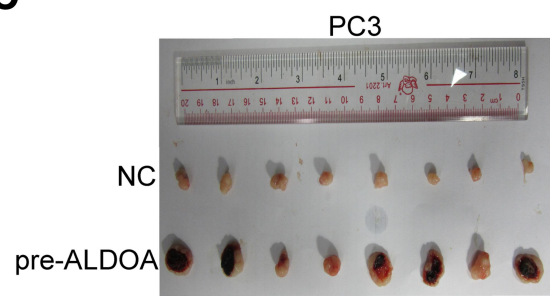

D

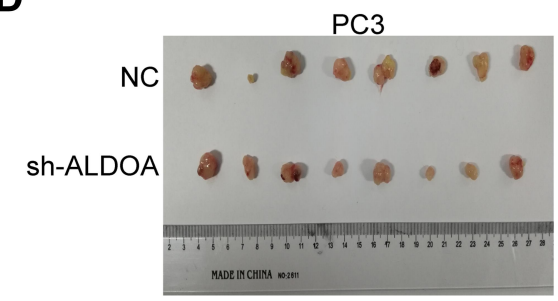

E

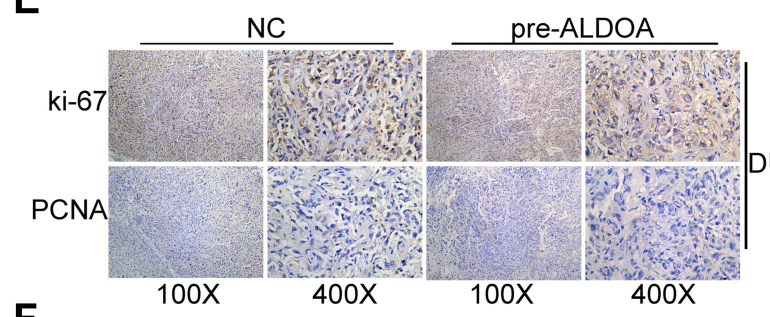

F

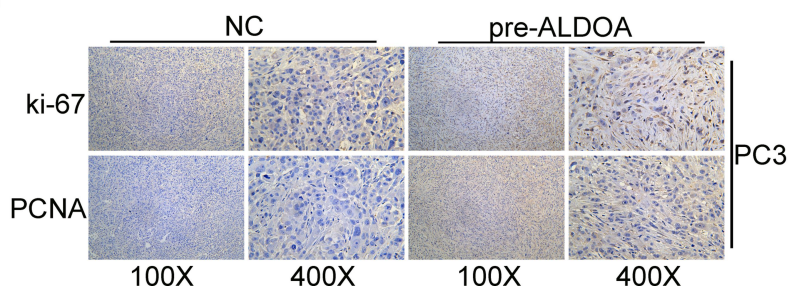

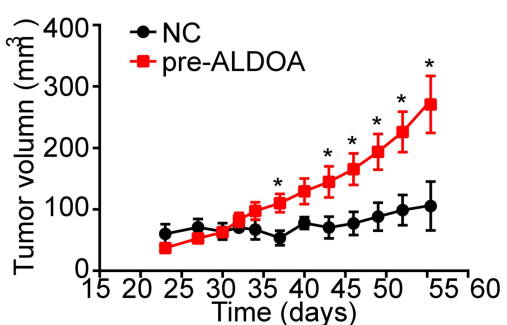
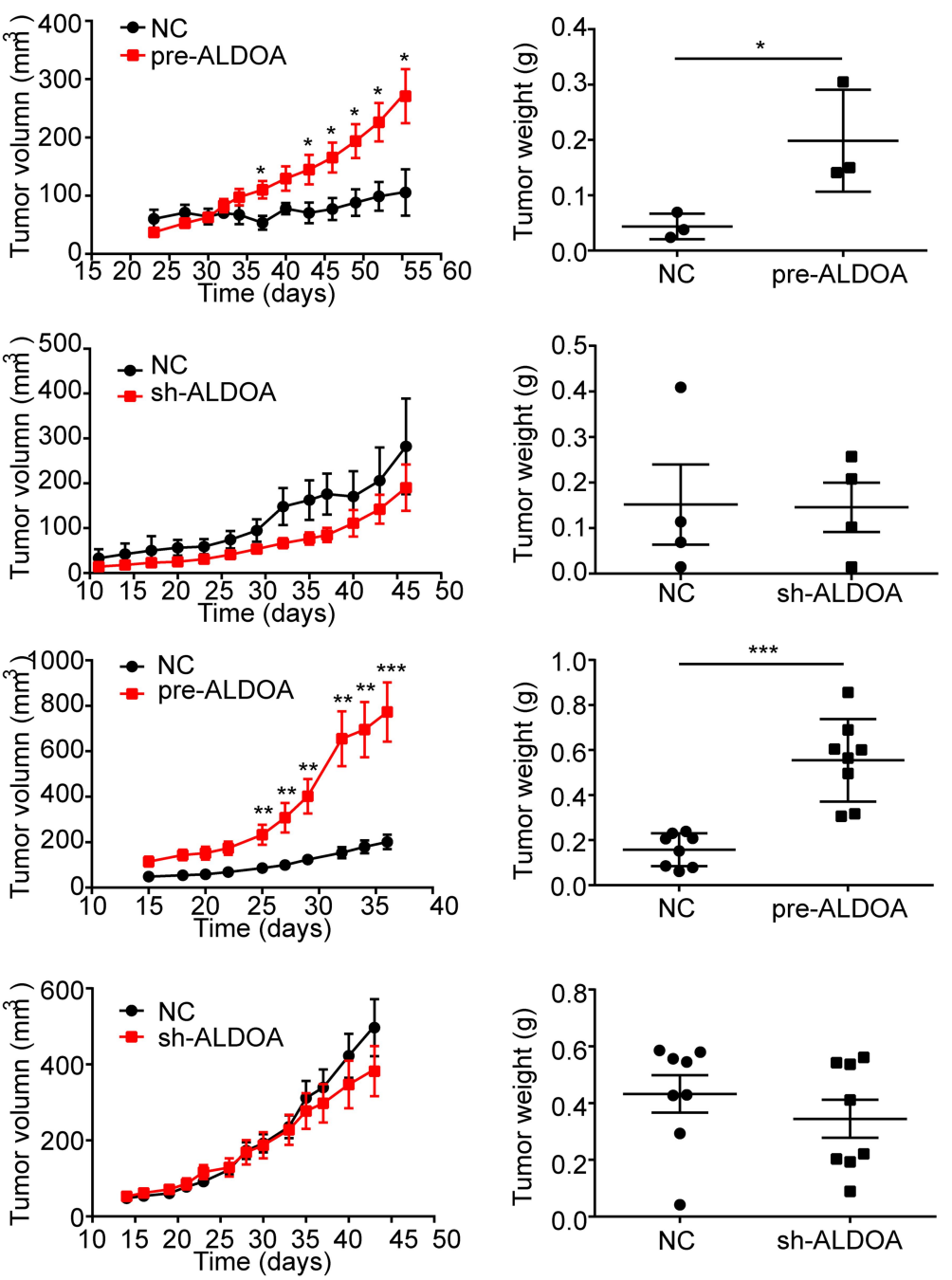

G

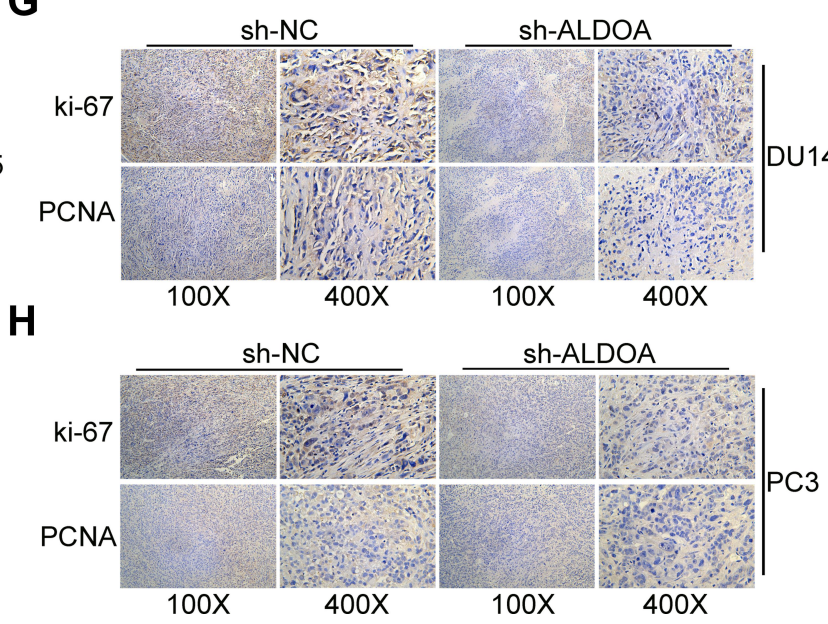

Figure 4 ALDOA promotes the tumor growth of PCa in nude mice in vivo and upregulates the expression of Ki67 and PCNA in the tumor tissues of nude mice. (A and $\mathbf{C}$ ) Overexpression of ALDOA enhances tumor growth of DUI45 and PC3 cells in the nude mice xenograft model. (B and D) Knockdown expression of ALDOA does not significantly inhibit tumor growth of DUI45 and PC3 cells in the nude mice xenograft model. (E and F) The immunohistochemistry score for Ki67 and PCNA in tumor tissues resulting from ALDOA overexpression in PC3 and DUI45 cell lines. (G and $\mathbf{H}$ ) The immunohistochemistry score for Ki67 and PCNA in the tumor tissues resulting from ALDOA knockdown in PC3 and DUI45 cell lines. Statistical analysis is shown as mean \pm SD.*P $<0.05$, **P $<0.01$, ***P $<0.001$ compared with the NC group. 
A

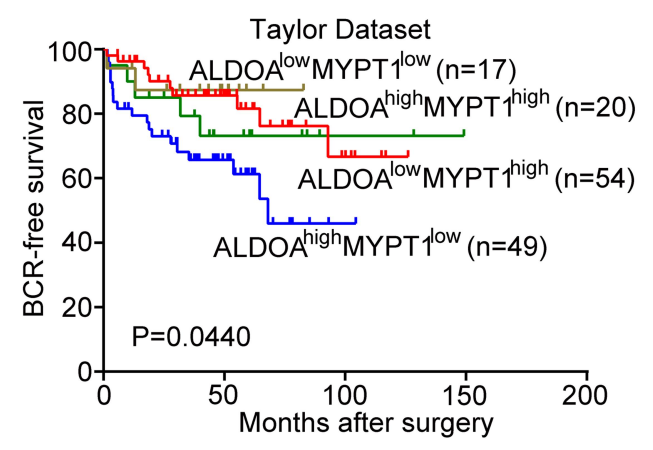

C

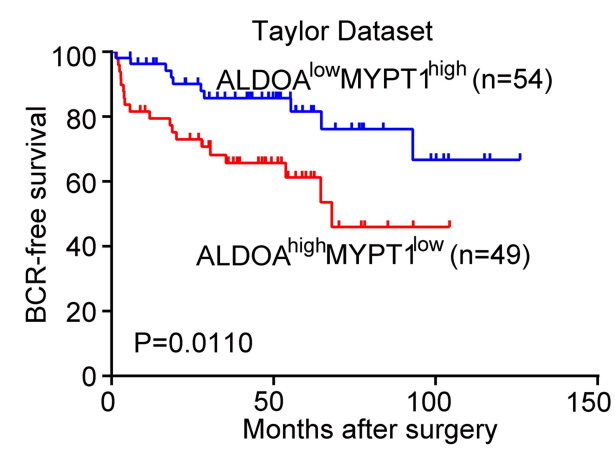

E

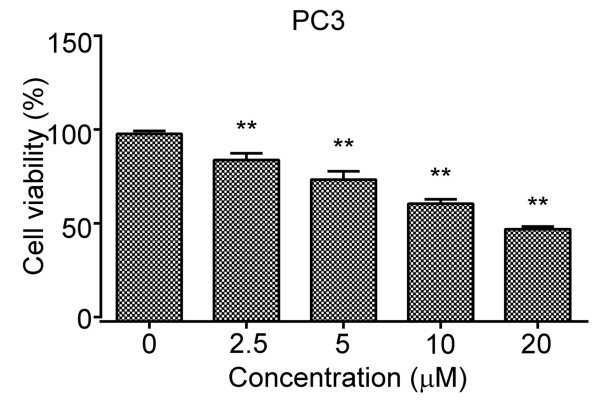

G

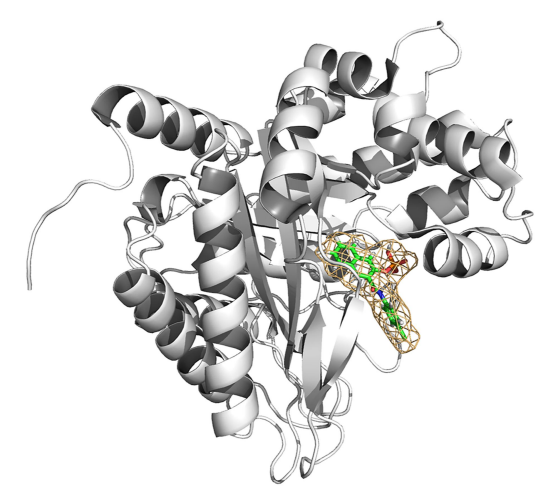

B

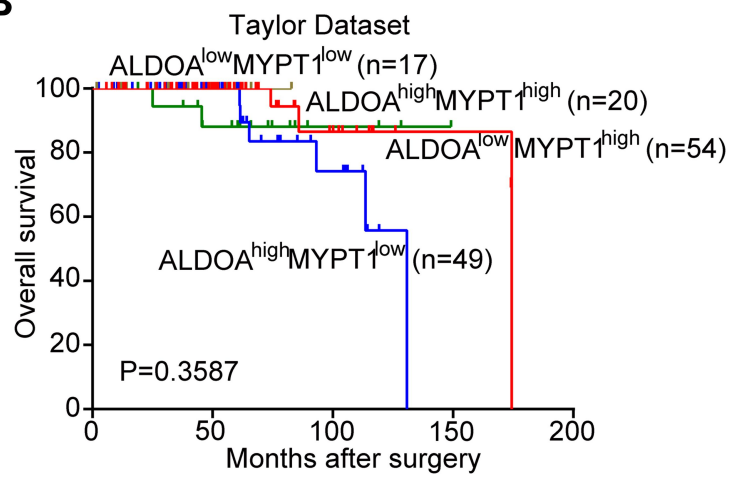

D

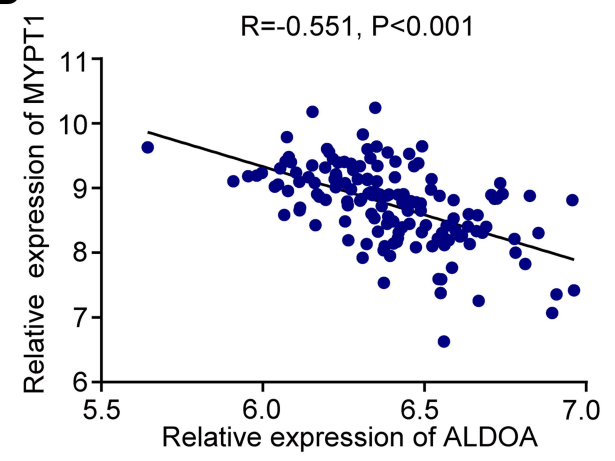

F

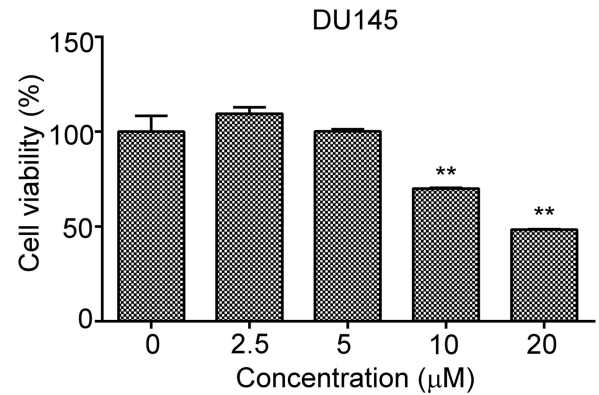

H

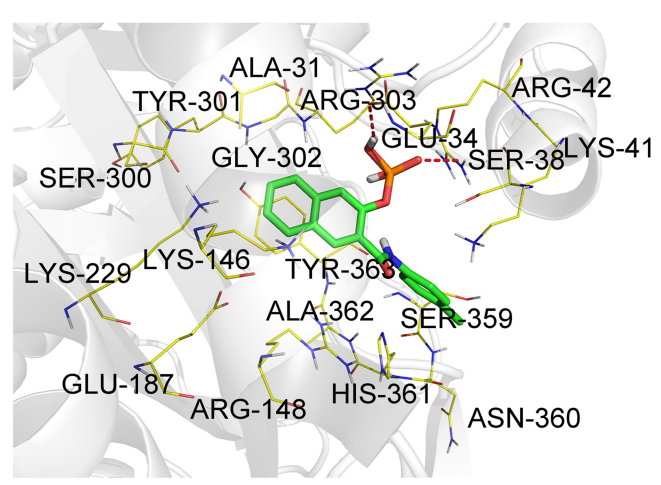

Figure 5 ALDOA expression is negatively correlated with MYPTI expression in the Taylor prostate cancer dataset. (A and B) Comparison of the overall biochemical recurrence-free survival rate and overall survival rate across different groups stratified according to MYPTI and ALDOA expression. (C) There was a significant difference in the overall biochemical recurrence-free survival rate between the groups with low MYPTI expression and high ALDOA expression and the groups with high MYPTI expression and low ALDOA expression. (D) The expression of ALDOA in the PCa of the Taylor Dataset was negatively correlated with MYPTI expression. (E) The cell viability of PC3 groups gradually decreased as the concentration of naphthol AS-E phosphate increased. (F) The cell viability of DUI 45 cells treated with a higher concentration of naphthol AS-E phosphate (I0 and $20 \mu \mathrm{moL} / \mathrm{L})$ was lower than that of the control group. ${ }^{* * P}<0.01$ compared with the NC group. (G-H) Molecular docking results of naphthol AS-E phosphate and aldolase A. (G) The association between the higher affinity molecules and the acceptor molecules and hydrophobic and hydrophilic regions is shown in green and pink, respectively. $(\mathbf{H})$ The mode of action between the molecule and the acceptor molecule showing the highest affinity. 
Table 3 Affinity Data Between Ligands and Receptors of 10 Molecular Models Were Obtained by Molecular Docking Simulations Between Naphthol AS-E Phosphate and Aldolase A

\begin{tabular}{|l|l|}
\hline Mode & Affinity (kcal/mol) \\
\hline 1 & -8.45 \\
\hline 2 & -7.66 \\
\hline 3 & -7.05 \\
\hline 4 & -6.94 \\
\hline 5 & -6.67 \\
\hline 6 & -6.26 \\
\hline 7 & -6.16 \\
\hline 8 & -6.10 \\
\hline 9 & -5.63 \\
\hline 10 & -5.37 \\
\hline
\end{tabular}

promotes the glycolysis of tumor cells. As an independent prognostic factor, its expression level is associated with the overall survival rate of cancer patients. Multiple studies have shown that ALDOA is highly expressed in tumor cells and in tissue samples of cancer patients, including pancreatic cancer, osteosarcoma, lung cancer, hepatocellular carcinoma, and colorectal cancer. Ji et al found that ALDOA was associated with the proliferation and metastasis of pancreatic cancer cells, and further, ALDOA predicted poor prognosis of pancreatic cancer. ${ }^{13}$ $\mathrm{Du}$ et al found expression levels of ALDOA were associated with metastasis, tumor grade, differentiation status, and poor prognosis of lung squamous cell carcinoma. ${ }^{16}$ Our findings using clinical data revealed that the upregulated protein expression of ALDOA was significantly correlated with postoperative metastasis and $\mathrm{BCR}$ of $\mathrm{PCa}$ patients. ALDOA was a risk factor for PCa progression and prognosis. ALDOA overexpression was associated with shorter BCR-free survival but did not function as an independent prognostic factor of $\mathrm{PCa}$ patients.

Previous studies have reported that ALDOA plays an essential role in cancer progression in a variety of tumors. The increased expression of ALDOA is significantly associated with the development and poor prognosis of various tumors. ${ }^{15-17,26-30}$ In our study, we found that ALDOA overexpression could promote the proliferation and cell cycle progression of $\mathrm{PCa}$ cells and inhibited the apoptosis of PCa cells in vitro. Meanwhile, ALDOA overexpression promoted tumor growth of $\mathrm{PCa}$ in nude mice in vivo. The IRS of PCNA and Ki67 revealed that overexpression of ALDOA significantly promoted cell proliferation, while ALDOA knockdown suppressed cell proliferation. Thus, both cell function experiments and animal experiments confirmed that ALDOA could promote the proliferation of PCa cells.

Studies have indicated that ALDOA is a downstream target of hypoxia-induced factor 1-alpha (HIF1- $\alpha) .{ }^{31-33}$ Kawai et al.'s findings demonstrated that under hypoxic conditions, ALDOA promoted glycolysis of colorectal cancer cells and enhanced the proliferation and invasion ability of colorectal cancer by regulating epithelialmesenchymal transformation and the cell cycle. Fructose diphosphate aldolase $\mathrm{A}$ is a key regulator of the hypoxic adaptation of colorectal cancer and has also been associated with treatment resistance and poor prognosis. ${ }^{30}$ Thus, we propose that the main mechanism underlying the biological effects of ALDOA's on PCa is to regulate the glycolytic processes of $\mathrm{PCa}$ cells, thereby affecting energy sources required for their growth and activity and the development of PCa.

An aldolase inhibitor, 2-phospho-naphthalene 6-diphosphate, has been reported to regulate the hyper-glycolysis observed in malignant tumors by targeting aldolase diphosphate. The results showed that the aldolase inhibitor could inhibit the cell proliferation of HELA liver cancer cells. ${ }^{33}$ Further, a longer-lasting inhibitory effect on glycolysis, HIF-1 activation, and cancer cell proliferation could be induced by blocking ALDOA or by silencing the ALDOA gene, with a consequent increase in the overall survival rate of a metastatic breast cancer transplanted tumor model. ${ }^{29}$ Naphthol AS-E phosphate is a competitive inhibitor of Aldolase A. It has been reported that Naphthol AS-E phosphate may inhibit the expression of Myb target genes and induce myeloid differentiation and apoptosis, and thus, might represent a therapeutic strategy for the treatment of leukemia. ${ }^{34}$ In this study, we found that naphthol AS-E phosphate suppressed the proliferation of two PCa cell lines with a significant dose-dependent effect. Molecular docking simulations confirmed that naphthol AS-E phosphate bound to aldolase A via both polar and non-polar forces. Therefore, we believe that the systemic application of naphthol AS-E phosphate might act as an inhibitor of aldolase A activity, thus interfering with the glycolytic process of $\mathrm{PCa}$ cells and controlling their growth. Treatment with aldolase A inhibitors may be 
considered a therapeutic option to inhibit the development of PCa.

MYPT1 may act as a tumor suppressor in $\mathrm{PCa},{ }^{12}$ while ALDOA is a glycolytic pathway-related protein which binds to MYPT1. Functionally, these proteins have been mostly involved in the tumor metabolic pathways. We found that there was a negative correlation between the expression of ALDOA and MYPT1 in patients with PCa. However, additional studies are needed to determine whether the MYPT1-ALDOA signaling axis influences the regulation of carbohydrate metabolism of $\mathrm{PCa}$ cells.

\section{Conclusions}

Our studies showed that ALDOA was a risk factor for $\mathrm{PCa}$ progression and prognosis. Up-regulation of ALDOA was significantly associated with metastasis and BCR rates after surgery of $\mathrm{PCa}$ but did not function as an independent prognostic factor of $\mathrm{PCa}$ patients. In addition, the overexpression of ALDOA promoted tumor growth of PCa. We propose that aldolase $\mathrm{A}$ inhibitors should be used to suppress the growth of $\mathrm{PCa}$; however, additional studies investigating targeted therapies of aldolase A in PCa at the cellular level and animal level are needed to ensure their validity and safety. Our findings suggest that the MYPT1ALDOA signaling axis may represent a new target for the clinical treatment of PCa patients.

\section{Abbreviations}

$\mathrm{PCa}$, prostate cancer; ALDOA, Fructose-bisphosphate aldolase A; Tissue microarray (TMA); IRS, immunoreactivity scores; PSA, prostate-specific antigen; CI, confidence interval; HR, hazard ratio; MYPT1, myosin phosphatase target subunit 1; TAP/MS, tandem affinity purification/mass spectrometry.

\section{Data Sharing Statement}

The datasets used and analyzed during the current study are available from the corresponding author on reasonable request.

\section{Ethics Approval}

All procedures performed in these studies involving human participants and animals were approved by the Research Ethics Committee of Guangzhou First People's Hospital and Guangzhou Medical University, Guangdong, China.

\section{Author Contributions}

All authors made a significant contribution to the work reported, whether that is in the conception, study design, execution, acquisition of data, analysis and interpretation, or in all these areas; took part in drafting, revising or critically reviewing the article; gave final approval of the version to be published; have agreed on the journal to which the article has been submitted; and agree to be accountable for all aspects of the work.

\section{Funding}

This study was supported by grants from the National Natural Science Foundation of China (82072813 and 81571427), the Natural Science Foundation of Guangdong Province (2018A030313668 and 2020A1515110640), the Fundamental Research Funds for Central Universities (2018MS18), the Science Foundation of Guangzhou First People's Hospital (M2019016 and Q2019020), the Science and Technology Fund of Guizhou Provincial Health Commision (gzwjkj2018-1094 and gzwjkj2019-1-133).

\section{Disclosure}

The authors report no conflicts of interest for this work.

\section{References}

1. Taitt HE. Global trends and prostate cancer: a review of incidence, detection, and mortality as influenced by race, ethnicity, and geographic location. Am J Mens Health. 2018;12:1807-1823. doi:10.1177/1557988318798279

2. Crawford ED, Higano CS, Shore ND, Hussain M, Petrylak DP. Treating patients with metastatic castration resistant prostate cancer: a comprehensive review of available therapies. $J$ Urol. 2015;194:1537-1547. doi:10.1016/j.juro.2015.06.106

3. Beltran H, Prandi D, Mosquera JM, et al. Divergent clonal evolution of castration resistant neuroendocrine prostate cancer. Nat Med. 2016;22:298-305. doi:10.1038/nm.4045

4. Dhanalakshmi S, Singh R. Silibinin strongly inhibits growth and survival of human endothelial cells via cell cycle arrest and downregulation of survivin, Akt and NF-kappaB: implications for angioprevention and antiangiogenic therapy. Oncogene. 2005;24:1188-1202. doi:10.1038/sj.onc.1208276

5. Pelicano H, Martin D, Xu R, Huang P. Glycolysis inhibition for anticancer treatment. Oncogene. 2006;25:4633-4646. doi:10.1038/sj. onc. 1209597

6. Sborov DW, Haverkos BM, Harris PJ. Investigational cancer drugs targeting cell metabolism in clinical development. Expert Opin Investig Drugs. 2015;24:79-94. doi:10.1517/13543784.2015.960077

7. Dwarakanath B, Jain V. Targeting glucose metabolism with 2-deoxyD-glucose for improving cancer therapy. Future Oncol. 2009;5:581-585. doi:10.2217/fon.09.44

8. Landau BR, Laszlo J, Stengle J, Burk D. Certain metabolic and pharmacologic effects in cancer patients given infusions of 2-deoxyD-glucose. J Natl Cancer Inst. 1958;21:485-494. 
9. Maher JC, Krishan A, Lampidis TJ. Greater cell cycle inhibition and cytotoxicity induced by 2-deoxy-D-glucose in tumor cells treated under hypoxic vs aerobic conditions. Cancer Chemother Pharmacol. 2004;53:116-122. doi:10.1007/s00280-003-0724-7

10. Ray U. Roy SS1: aberrant lipid metabolism in cancer cells - the role of oncolipid-activated signaling. FEBS J. 2018;285:432-443. doi:10.1111/febs.14281

11. Lin ZY, Chen G, Zhang YQ, et al. MicroRNA-30d promotes angiogenesis and tumor growth via MYPT1/c-JUN/VEGFA pathway and predicts aggressive outcome in prostate cancer. Mol Cancer. 2017;16:48. doi:10.1186/s12943-017-0615-x

12. Liang Y, Zhuo Y, Lin Z, et al. Decreased Expression of MYPT1 Contributes To Tumor Angiogenesis and Poor Patient Prognosis in Human Prostate Cancer. Curr Mol Med. 2018;18(2):100-108. doi:10.2174/1566524018666180705111342

13. Ji S, Zhang B, Liu J, et al. ALDOA functions as an oncogene in the highly metastatic pancreatic cancer. Cancer Lett. 2016;374:127-135. doi:10.1016/j.canlet.2016.01.054

14. Shi S, Ji S, Qin Y, et al. Metabolic tumor burden is associated with major oncogenomic alterations and serum tumor markers in patients with resected pancreatic cancer. Cancer Lett. 2015;360:227-233. doi:10.1016/j.canlet.2015.02.014

15. Long F, Cai X, Luo W, Chen L, Li K. Role of aldolase A in osteosarcoma progression and metastasis: in vitro and in vivo evidence. Oncol Rep. 2014;32:2031-2037. doi:10.3892/or.2014.3473

16. Du S, Guan Z, Hao L, et al. Fructose-bisphosphate aldolase A is a potential metastasis-associated marker of lung squamous cell carcinoma and promotes lung cell tumorigenesis and migration. PLoS One. 2014;9:e85804. doi:10.1371/journal.pone.0085804

17. Chang L, Ni J, Beretov J, et al. Identification of protein biomarkers and signaling pathways associated with prostate cancer radio resistance using label-free LC-MS/MS proteomic approach. Sci Rep. 2017;7:41834. doi:10.1038/srep41834

18. Taylor BS, Schultz N, Hieronymus H, et al. Integrative genomic profiling of human prostate cancer. Cancer Cell. 2010;18:11-22. doi:10.1016/j.ccr.2010.05.026

19. Cai C, Chen Q-B, Han Z-D, et al. miR-195 inhibits tumor progression by targeting RPS6KB1 in Human Prostate Cancer. Clin Cancer Res. 2015;21:4922-4934. doi:10.1158/1078-0432.CCR-15-0217

20. Vander Heiden MG, Cantley LC, Thompson CB. Understanding the Warburg effect: the metabolic requirements of cell proliferation. Science. 2009;324:1029-1033. doi:10.1126/science.1160809

21. Patel CH, Powell JD. Warburg meets epigenetics [J]. Science. 2016;354:419-420. doi:10.1126/science.aak9776

22. Massie CE, Lynch A, Ramos-Montoya A, et al. The androgen receptor fuels prostate cancer by regulating central metabolism and biosynthesis. EMBO J. 2011;30:2719-2733. doi:10.1038/ emboj.2011.158
23. Gonzalez-Menendez P, Hevia D, Alonso-Arias R, et al. GLUT1 protects prostate cancer cells from glucose deprivation-induced oxidative stress. Redox Biol. 2018;17:112-127. doi:10.1016/j. redox.2018.03.017

24. Fendt SM, Bell EL, Keibler MA, et al. Metformin decreases glucose oxidation and increases the dependency of prostate cancer cells on reductive glutamine metabolism. Cancer Res. 2013;73:4429-4438. doi:10.1158/0008-5472.CAN-13-0080

25. Rose IA, O'Connell EL. Studies on the interaction of aldolase with substrate analogues. J Biol Chem. 1969;244:126-134. doi:10.1016/ S0021-9258(19)78201-5

26. Xin Li, Fengxing Jiang, Zhong Ge, et al. Fructose-Bisphosphate Aldolase A Regulates Hypoxic Adaptation in Hepatocellular Carcinoma and Involved with Tumor Malignancy. Dig Dis Sci. 2019;64(11):3215-3227. doi:10.1007/s10620-019-05642-2. Epub 2019 Apr 30

27. Yamamoto T, Kudo M, Peng WX, et al. Identification of aldolase A as a potential diagnostic biomarker for colorectal cancer based on proteomic analysis using formalin-fixed paraffin-embedded tissue. Tumour Biol. 2016;37:13595-13606. doi:10.1007/s13277-016-5275-8

28. Fu H, Gao H, Qi X, et al. Aldolase A promotes proliferation and G1/S transition via the EGFR/MAPK pathway in non-small cell lung cancer. Cancer Commun. 2018;38:18. doi:10.1186/s40880-018-0290-3

29. Grandjean G, de Jong PR, James B, et al. Definition of a novel feedforward mechanism for glycolysis-HIF $1 \alpha$ signaling in hypoxic tumors highlights Aldolase A as a therapeutic target. Cancer Res. 2016;76:4259-4269. doi:10.1158/0008-5472.CAN-16-0401

30. Kawai K, Uemura M, Munakata K, et al. Fructose-bisphosphate aldolase $\mathrm{A}$ is a key regulator of hypoxic adaptation in colorectal cancer cells and involved in treatment resistance and poor prognosis. Int J Oncol. 2017;50:525-534. doi:10.3892/ijo.2016.3814

31. Semenza GL, Roth PH, Fang HM, Wang GL. Transcriptional regulation of genes encoding glycolytic enzymes by hypoxia-inducible factor 1. J Biol Chem. 1994;269:23757-23763. doi:10.1016/S00219258(17)31580-6

32. Sharp FR, Bernaudin M. HIF1 and oxygen sensing in the brain. Nat Rev Neurosci. 2004;5:437-448. doi:10.1038/nrn1408

33. Heron PW, Abellán-Flos M, Salmon L, Sygusch J. Bisphosphonate inhibitors of mammalian glycolytic aldolase. $J$ Med Chem. 2018;61:10558-10572. doi:10.1021/acs.jmedchem.8b01000

34. Uttarkar S, Dukare S, Bopp B, et al. Phosphate inhibits the activity of the transcription factor myb by blocking the interaction with the KIX domain of the coactivator p300. Mol Cancer Ther. 2015;14:1276-1285. doi:10.1158/1535-7163.MCT-14-0662
OncoTargets and Therapy

\section{Publish your work in this journal}

OncoTargets and Therapy is an international, peer-reviewed, open access journal focusing on the pathological basis of all cancers, potential targets for therapy and treatment protocols employed to improve the management of cancer patients. The journal also focuses on the impact of management programs and new therapeutic agents and protocols on patient perspectives such as quality of life, adherence and satisfaction. The manuscript management system is completely online and includes a very quick and fair peer-review system, which is all easy to use. Visit http://www.dovepress.com/ testimonials.php to read real quotes from published authors. 